\title{
Chromosomal Location and Genetic Relationship of Leaf Rust Resistance Genes Rph9 and Rph12 in Barley
}

\author{
I. G. Borovkova, Y. Jin, and B. J. Steffenson
}

First and third authors: Department of Plant Pathology, North Dakota State University, Fargo 58105; second author: Plant Science Department, South Dakota State University, Brookings 57007.

Current address of I. Borovkova: Monsanto, 700 Chesterfield Parkway North, GG4A, St. Louis, MO 63198.

Accepted for publication 21 October 1997.

\begin{abstract}
Borovkova, I. G., Jin, Y., and Steffenson, B. J. 1998. Chromosomal location and genetic relationship of leaf rust resistance genes Rph 9 and Rph12 in barley. Phytopathology 88:76-80.

Barley lines Hor 2596 and Triumph are the sources of leaf rust resistance genes $R p h 9$ and $R p h 12$, respectively. An allelism test was performed with $\mathrm{F}_{2}$ progeny of the cross Triumph/Hor 2596 inoculated with Puccinia hordei. No recombinants were found in a population of 3,858 progeny, indicating $R p h 9$ and $R p h 12$ are alleles. Molecular and morphological markers were used to identify the chromosomal location of these genes in the crosses Bowman/Hor 2596 and Triumph/I91-533-va. A linkage was detected between $R p h 9$ and the flanking sequence-tagged site

(STS) markers $A B C 155$ and $A B G 3$ on chromosome $7(5 \mathrm{H})$ at a distance of 20.6 and 20.1 centimorgans (cM), respectively, and to the microsatellite marker dehydrin-9 (HVDHN9) at a distance of $10.2 \mathrm{cM}$ in the Bowman/ Hor 2596 cross. Analysis of isozymes in bulks of the same population showed that $R p h 9$ may be closely linked to the Est 9 locus on chromosome $7(5 \mathrm{H})$. The Rph12 locus was linked to the morphological trait locus $v a$ (controlling variegated leaf color) on chromosome $7(5 \mathrm{H})$ at a distance of $22.6 \mathrm{cM}$ in the Triumph/I91-533-va cross. Rph12 also was linked with STS marker ABC155 (24.4 cM) and RAPD marker OPA19 (1.5) $(17.8 \mathrm{cM})$. These data indicate that Hor 2596 and Triumph carry a leaf rust resistance gene at the same locus on the long arm of chromosome $7(5 \mathrm{H})$ of barley.
\end{abstract}

Leaf rust of barley (Hordeum vulgare L.), caused by Puccinia hordei G. Otth, is considered one of the most important rust diseases of the crop. Although widespread and severe epidemics of leaf rust have historically been rare, local epidemics in the United States, Australia, and Europe have resulted in significant losses to barley crops $(5,7,10)$. In the United States, sporadic outbreaks of leaf rust have occurred in the Mid-Atlantic and Upper Midwest regions $(10,27)$. The use of resistant cultivars is the best control measure for the disease. To date, 14 genes for resistance to $P$. hordei (Rph genes, formerly $P a$ ) have been identified in barley and its wild progenitor, $H$. vulgare ssp. spontaneum (C. Koch) Thell. $(8,13,14,25)$. The line Hor 2596 (CI 1243) is the source of Rph9 $(29,31)$. This gene was thought to be present in some European barley cultivars, including the East German release Trumpf and its derived export selection Triumph (5). Further studies showed, however, that Hor 2596 and Triumph exhibited different infection types (ITs) in response to some $P$. hordei isolates (15). In a genetic study, Walther (33) detected three resistance genes in Trumpf: two with dominant gene action and one with recessive gene action. None of these genes were considered to be the same as Rph 9 in Hor 2596 (33). In a more recent genetic study, a single resistance gene was identified in Triumph and designated Rph12 (14). This single-gene inheritance pattern of Triumph to leaf rust was corroborated in two subsequent studies $(3,13)$.

Information regarding the chromosomal location of disease resistance genes could facilitate their efficient transfer in breeding programs. Unfortunately, definitive data on the chromosomal position of leaf rust resistance genes $R p h 9$ and $R p h 12$ are lacking. Jin et al. (14) identified chromosome $7(5 \mathrm{H})$ as the putative loca-

Corresponding author: B. J. Steffenson

E-mail address: bsteffen@badlands.nodak.edu

Publication no. P-1997-1201-01R

(C) 1998 The American Phytopathological Society tion of Rph12, but this was based on distant linkage (recombination values of 26.1 and $39.3 \%$, respectively) with the chromosome $7(5 \mathrm{H})$ morphological trait loci rawl (controlling the degree of barbing on the awns) and srh (controlling the length of hairs on the rachilla). Thus, this study was undertaken to identify the chromosomal location of Rph 9 and Rph12, using both morphological and molecular markers. Additionally, we investigated the allelic relationship between the resistance gene in Triumph and Rph9 in Hor 2596.

\section{MATERIALS AND METHODS}

Plant materials. Barley line Hor 2596 (CI 1243) and cv. Triumph (provided by M. Johnston, Montana State University, Bozeman) were used as the donors of $R p h 9$ and $R p h 12$, respectively, in crosses. Bowman (PI 483237) was used as the susceptible parent in the cross with Hor 2596. Line I91-533-va, a near-isogenic line of Bowman, which has the chromosome $7(5 \mathrm{H})$ morphological trait locus $v a$ (controlling variegated leaf color), was crossed with Triumph. Line I91-533-va was used to test whether va might be linked to Rph12. Like Bowman, I91-533-va is susceptible to leaf rust. $\mathrm{F}_{2}$ populations from the Bowman/Hor 2596 and Triumph/I91-533-va crosses were derived from single $F_{1}$ plants and consisted of 360 and 63 progeny, respectively. $F_{3}$ families of both crosses were evaluated for their leaf rust reaction to identify the genotypes of $\mathrm{F}_{2}$ plants. Homozygous $\mathrm{F}_{2}$ plants were used to create DNA bulks for bulked segregant analysis (24). For each population, two DNA bulks were made: one consisting of DNA from 10 homozygous resistant plants, and one consisting of DNA from 10 homozygous susceptible plants. Primers amplifying products that exhibited polymorphisms between the DNA bulks as well as between the parents subsequently were evaluated on all 63 progeny from the Triumph/ I91-533-va population and on 134 randomly selected progeny from the Bowman/Hor 2596 population. In addition to the two mapping populations, a cross also was made between Hor 2596 
and Triumph to test for allelism between Rph9 and Rph12. This population consisted of $3,858 \mathrm{~F}_{2}$ plants.

Wheat-barley addition lines and two doubled haploid populations of barley were utilized to position molecular markers on the barley chromosomes. The wheat-barley ditelosomic addition lines (except chromosome 5) of Islam (12) were used to determine the chromosome on which molecular markers were located. The doubled haploid populations of Steptoe/Morex (17) and Q21861/SM89010 (28) were used to further position some of the molecular markers on the identified chromosome. The Steptoe/Morex population is useful for this purpose because a highly saturated molecular map has been developed for it (17). Moreover, several key disease resistance genes and molecular markers have been positioned in the Q21861/SM89010 population (4,28).

Leaf rust evaluations. Seeds of parental, $F_{1}, F_{2}$, and $F_{3}$ plants were sown in plastic pots filled with a peat moss/perlite $(3: 1)$ potting mixture and grown at $22 \pm 3^{\circ} \mathrm{C}$ in a greenhouse, with supplemental lighting provided by $1,000-\mathrm{W}$ metal halide bulbs (530 to $710 \mu \mathrm{mol}$ photon $\mathrm{m}^{-2} \mathrm{~s}^{-1}$ ) for $13 \mathrm{~h}$ /day. One-week-old seedlings (primary leaves fully expanded) were inoculated with urediniospores of isolate ND8702 of $P$. hordei suspended in a light-weight mineral oil (Soltrol 170, Phillips Petroleum Company, Bartlesville, OK). In the allelism test, 996 progeny were inoculated with isolate ND8702, 1,420 were inoculated with isolate BLR4, and 1,442 were inoculated with isolate Aus220. These three P. hordei isolates are all avirulent on Hor 2596 and Triumph. A concentration of $\approx 3.5 \mathrm{mg}$ of urediniospores per $\mathrm{ml}$ of oil was used. Inoculated plants were placed in chambers $\left(20^{\circ} \mathrm{C}\right)$ maintained near saturation by periodic mistings from ultrasonic humidifiers. After a 16-h misting period in the dark, plants were allowed to dry slowly before being returned to the greenhouse. The ITs exhibited by plants in response to $P$. hordei were evaluated based on the rating scale of Levine and Cherewick (21) 12 to 14 days after inoculation.

Molecular markers. Several types of markers were used to position the leaf rust resistance genes on barley chromosomes, including random amplified polymorphic DNAs (RAPDs), sequencetagged sites (STSs), simple sequence repeats (SSRs) or microsatellites, and isozymes. One hundred eighty arbitrary random primers sets, A, B, E, H, K, N, O, P, and T, from Operon Technologies (Alameda, CA) and one hundred fifty STS polymerase chain reaction (STS-PCR) primer sets from the Montana State University Barley Genetics Laboratory, Bozeman (provided by T. K. Blake), were used to identify markers linked to $R p h 9$ and $R p h 12$. The STS primers (each $\approx 20$ bp long) were developed from restriction fragment length polymorphism (RFLP) markers previously mapped to barley chromosomes. Sequences for the STS primers are available on-line at the Graingenes website (supported by the U.S. Department of Agriculture and the National Agricultural Library). Markers generated by STS primers that were not polymorphic in the par-

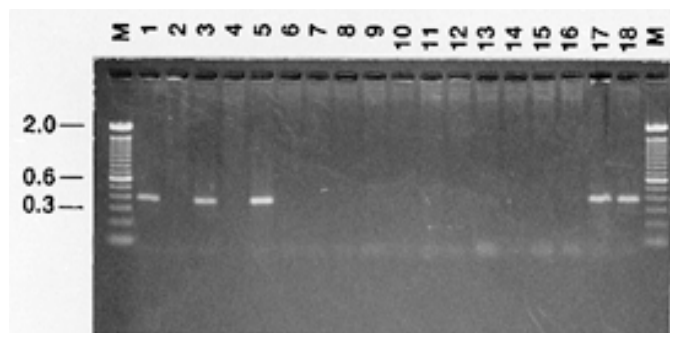

Fig. 1. Analysis to determine the chromosomal location of the $A B C 155$ sequence-tagged site marker generated by polymerase chain reaction with wheatbarley addition lines. Lanes 1 through 5, DNA of barley lines Bowman (lane 1), Hor 2596 (lane 2), Steptoe (lane 3), Morex (lane 4), and Betzes (lane 5). Lane 6, DNA of wheat parent Chinese Spring. Lanes 7 through 18, DNA of wheat lines carrying barley chromosome arms $1 \alpha$ (lane 7), $1 \beta$ (lane 8), 2S (lane 9), 2L (lane 10), 3S (lane 11), 3L (lane 12), 4S (lane 13), 4L (lane 14), 6S (lane 15), 6L (lane 16), 7L (lane 17), and 7L (lane 18). Lane M, DNA size markers (100-bp ladder). ents after amplification were restricted with HaeIII, HinfI, HhaI, RsaI, or TaqI endonuclease, according to the manufacturer's instructions (New England Biolabs Inc., Beverly, MA). Methods for DNA isolation from plants and PCR amplification were as previously described (4). Protocols for the STS primers were as described by Tragoonrung et al. (30). PCR amplification of microsatellites (SSRs) previously mapped to chromosome $7(5 \mathrm{H})$ (22) was performed according to Yu et al. (34). The primers for HVDHN9 (X152572, mRNA for dehydrin-9) and HVDHN7 (X71362, gene for dehydrin-7) are described in Becker and Heun (1) and were synthesized by Gibco BRL Life Technologies (Gaithersburg, MD). PCR products were separated on a denaturing polyacrylamide gel with $6 \mathrm{M}$ urea and on a nondenaturing $5 \%$ polyacrylamide gel in cases in which the PCR reaction did not contain a radioactive label. The nondenaturing gels were stained with ethidium bromide to visualize the DNA fragments on a UV transilluminator. Esterase isozymes in the primary leaves of 1-week-old plants from the Bowman/Hor 2596 population were analyzed in starch gels, according to the protocols of Hvid and Nielsen (11).

Data analysis. The chi-square method was used to test the hypothesis of independent segregation in $\mathrm{F}_{2}$ populations, and the method of maximum likelihood was used to calculate linkage distances from $\mathrm{F}_{2}$ data. Segregating molecular markers were scored for each progeny, and linkage analyses were performed with the MAPMAKER software program, version 3.0 (20). The Kosambi (18) mapping function was used to convert recombination frequencies to map distances in centimorgans.

\section{RESULTS}

Genetic studies. In the Bowman/Hor 2596 cross, the total $F_{2}$ progeny population segregated $268: 92$ (resistant/susceptible) to isolate ND8702 of $P$. hordei, indicating resistance to leaf rust was conferred by a single gene $\left(\chi_{3: 1}^{2}=0.06 ; P=0.81\right)$ in Hor 2596 . Similar results were obtained in the Triumph/191-533- $v a$ cross, in which $\mathrm{F}_{2}$ progeny segregated $43: 20$ for resistance and susceptibility $\left(\chi_{3: 1}^{2}=1.53 ; P=0.22\right)$. No segregation for leaf rust reaction was observed in the cross between Triumph and Hor 2596 for the allelism test. All 3,858 $\mathrm{F}_{2}$ plants inoculated with isolate ND8702, BLR4, or Aus220 exhibited resistant ITs (0; to 2), indicating Rph 9 and $R p h 12$ are alleles.

Mapping of Rph12. In the Triumph/I91-533-va cross, Rph12 was linked with the morphological trait locus $v a$ on chromosome $7(5 \mathrm{H})$ at a distance of 22.6 centimorgans $(\mathrm{cM})$. An attempt was made to saturate this region with additional markers by evaluating 180 RAPD primers in the bulks; however, only 1 RAPD marker, OPA19 (1.5), was found to be linked $(17.8 \mathrm{cM})$ to $R p h 12$. The linkage distance between $v a$ and OPA19 (1.5) was $11.4 \mathrm{cM}$. One hundred fifty STS-PCR primer sets for different chromosomes

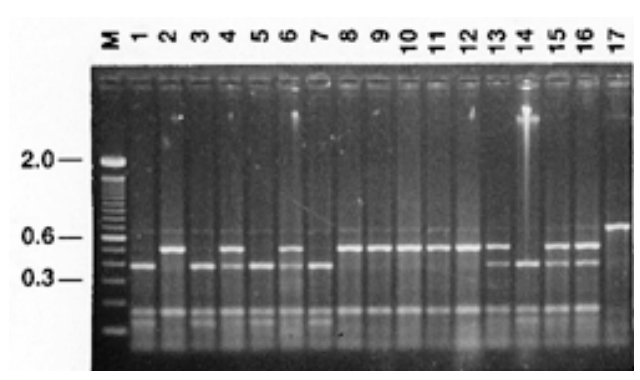

Fig. 2. Ethidium bromide-stained agarose gel of polymerase chain reaction amplification generated by ABG3 STS primers in the Bowman/Hor 2596 barley population after HinfI restriction. Lane 1, Bowman parent; lane 2, Hor 2596 parent; lanes 3 through 7 , homozygous susceptible $\mathrm{F}_{2}$ plants; lanes 8 through 12 , homozygous resistant $F_{2}$ plants; lanes 13 through 16 , heterozygous $F_{2}$ plants (lanes 6 and 14 represent recombinants); lane 17, nonrestricted fragment; and lane M, DNA size markers (100-bp ladder). 
also were analyzed in the bulks, with special emphasis on possible chromosome $7(5 \mathrm{H})$ STS markers. STS marker $A B C 155$ was linked with Rph12 at distance of a $24.4 \mathrm{cM}$. STS marker $A B C 155$ was mapped to chromosome $7(5 \mathrm{H})$ by analysis of the wheat-barley addition lines (Fig. 1). The position of this marker on chromosome $7(5 \mathrm{H})$ was determined by its cosegregation with RFLP marker $A B C 155$ in the Steptoe/Morex population (data not shown). Seven other chromosome $7(5 \mathrm{H})$ STS markers $(A B G 3, A B C 717$, $A B G 473, A B C 302, A B G 712, A B G 390$, and $A B C 168)$ were evaluated in this study but were not polymorphic in this cross after amplification and restriction with HaeIII, HinfI, HhaI, RsaI, or TaqI endonuclease.

Mapping of Rph9. Because the allelism test revealed that $R p h 12$ and $R p h 9$ were either allelic or very closely linked, the same chromosome $7(5 \mathrm{H})$ markers used to map Rph12 in the Triumph/I91-533-va cross also were used to map Rph9 in the Bowman/Hor 2596 cross. No linkage was found between any of the 180 RAPD markers and Rph9 in the Bowman/Hor 2596 population. RAPD marker OPA19 (1.5) was not polymorphic in this population. However, a linkage was found between $R p h 9$ and STS markers $A B C 155$ and $A B G 3$. STS markers $A B C 155$ and $A B G 3$ flank $R p h 9$ at a distance of 20.6 and $20.1 \mathrm{cM}$, respectively. Both markers are located on chromosome $7(5 \mathrm{H})$. STS marker $A B G 3$ (Fig. 2) was polymorphic after restriction with HinfI in both the Bowman/Hor 2596 and Q21861/SM89010 populations. Its chromosomal location was determined in the latter population by linkage with stem rust resistance gene rpg4 (31.7 cM) and RFLP marker $M W G 740(30.6 \mathrm{cM})$, which were previously positioned on chromosome 7(5H) (4).

The putative location of $R p h 9$ on chromosome $7(5 \mathrm{H})$, as determined by linkage with the STS markers, placed the gene in the vicinity of the Est9 locus, based on the Steptoe/Morex map (17). Analysis of esterase isozymes in Bowman and Hor 2596 revealed polymorphisms for Est2, Est4, and Est 9 . A distinct band intensity polymorphism for Est9 was found in the bulks of homozygous resistant and homozygous susceptible $\mathrm{F}_{3}$ families from the Bowman/Hor 2596 cross ( $F_{2}$ plants were not available), suggesting Rph 9 may be closely linked to the Est 9 locus on chromosome 7(5H). No polymorphism for Est 2 or Est 4 was detected in these bulks. Analysis of $40 \mathrm{~F}_{3}$ families revealed that Est 9 and Rph 9 were linked at a distance of $9.3 \mathrm{cM}$, although the activity of esterase 9 was low and the fragments were not always easy to score. To further corroborate the chromosome $7(5 \mathrm{H})$ location of $R p h 9$, we evaluated the HVDHN7 and HVDHN9 microsatellites, which were previously mapped to this chromosome by Liu et al. (22). HVDHN7 and HVDVN9 were analyzed in the parental lines in both a nondenaturing and a denaturing polyacrylamide gel. HVDHN7 was not polymorphic in the Bowman/Hor 2596 population. In contrast, the HVDHN9 primers generated several fragments, one of which (a $0.128-\mathrm{kb}$ fragment) was polymorphic and distinct in both gels. Thus, the entire population was analyzed for this SSR in a $5 \%$ nondenaturing polyacrylamide gel. Rph9 was linked to $H V D H N 9$ at a distance of $10.2 \mathrm{cM}$. Linkage maps showing the relationship between the two leaf rust resistance genes and associated markers in the Bowman/Hor 2596 and Triumph/I91-533-va populations are given in Figure 3.

\section{DISCUSSION}

No recombinants were detected in the allelism test between the sources of Rph9 (Hor 2596) and Rph12 (Triumph) when 3,858 progeny were evaluated. This result indicates $R p h 9$ and $R p h 12$ are allelic. Clifford and Jones (6) were the first to suggest that Hor 2596 and Triumph may have different leaf rust resistance genes, after showing that the two lines exhibited distinctly different reactions to isolate 673 of $P$. hordei. This result was subsequently confirmed by others (33; B. J. Steffenson and Y. Jin, unpublished data). Based on the analysis of reciprocal crosses of Hor 2596 and Trumpf, Walther (33) concluded that different genes were present in the two lines, despite the fact that they gave similar seedling

\section{Bowman/Hor 2596}

\section{Chromosome $7(5 \mathrm{H})$}

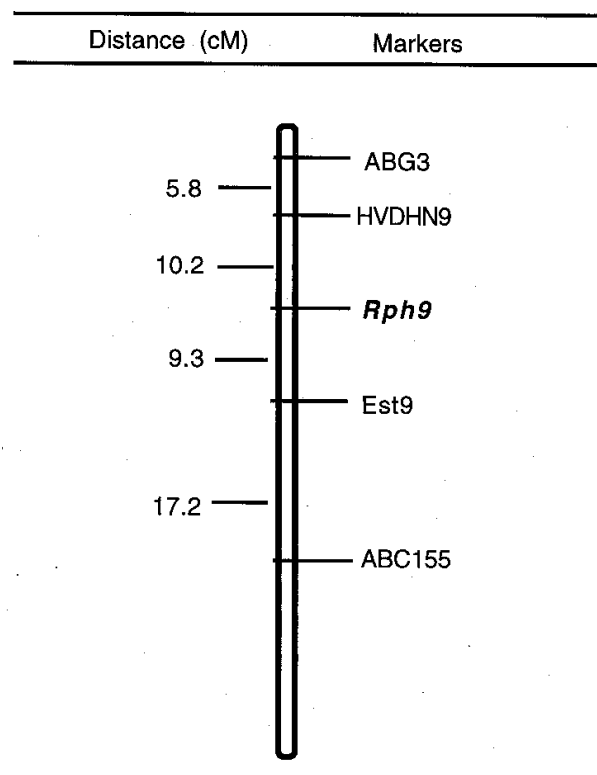

\section{Triumph/191-533-va}

Chromosome $7(5 \mathrm{H})$

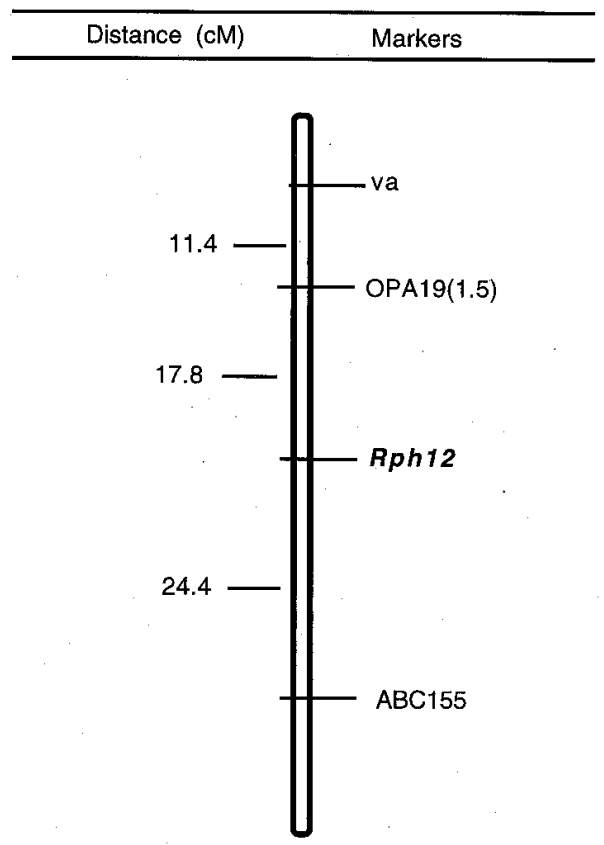

Fig. 3. Linkage maps showing the relationship between two leaf rust resistance genes (Rph9 and Rph12) and associated markers in the Bowman/Hor 2596 and Triumph/I91-533-va barley populations. Distances (centimorgans) were calculated from recombination percentages by the Kosambi function (18). The map is oriented with the upper portion of the chromosome toward the centromere of chromosome $7(5 \mathrm{H})$. 
reactions to $P$. hordei. The genes in Hor 2596 were detected against $P$. hordei pathotypes that were either avirulent or virulent for Trumpf, indicating none of the dominant genes in Trumpf were identical to Rph9 in Hor 2596 (33). Walther (33) suggested the presence of two dominant or partially dominant resistance genes in Trumpf detected against avirulent pathotypes and one recessive gene detected against virulent pathotypes. Two additional recessive genes acting complementary to each other were hypothesized in Hor 2596 (33). Jin et al. (14) detected one incompletely dominant gene in Triumph against isolate ND8702 of $P$. hordei. This result was confirmed in this and two other studies involving Triumph $(3,13)$. The different results obtained by Walther (33) and our group may be explained by the use of two different barley lines, each with a different number of leaf rust resistance genes. Walther (33) used the East German cv. Trumpf in her studies, whereas we used Triumph, an export selection from Trumpf. Our data clearly show the presence of a single leaf rust resistance gene in both Hor 2596 and Triumph to isolate ND8702.

In two different populations (Bowman/Hor 2596 and Triumph/ I91-533-va), Rph9 and Rph12 were linked to a common molecular marker, $A B C 155$, at a distance of 20.6 and $24.4 \mathrm{cM}$, respectively. STS marker $A B C 155$ was positioned on chromosome $7(5 \mathrm{H})$, using the wheat-barley addition lines (T. K. Blake, personal communication; and this study, Fig. 1). The linkage identified with $A B C 155$ places both Rph 9 and Rph12 on the long arm of chromosome 7(5H). Rph9 also showed linkage $(20.1 \mathrm{cM})$ with STS marker $A B G 3$. The primers for this STS marker were developed from the $A B G 3$ RFLP clone, which produces a marker on chromosome $4(4 \mathrm{H})$ in the Steptoe/Morex population. However, this clone also produces RFLP marker $A B G 3 B$ that maps to chromosome $7(5 \mathrm{H})$ in other barley crosses (e.g., Harrington/Morex, [16]). Thus, ABG3 identifies two distinct genetic loci on chromosomes $4(4 \mathrm{H})$ and $7(5 \mathrm{H})$ in barley. Linkage with markers on chromosome $7(5 \mathrm{H})$ (i.e., rpg4 and $M W G 740$ ) in the Q21861/SM89010 population led us to conclude that the STS marker generated by the ABG3 primers is located on chromosome $7(5 \mathrm{H})$ and not on chromosome $4(4 \mathrm{H})$.

The putative location of the Rph9 locus on chromosome $7(5 \mathrm{H})$ was determined by analysis of linkage with Est9. A distinct band intensity polymorphism for $E s t 9$ in resistant and susceptible $\mathrm{F}_{3}$ family bulks strongly suggested that $R p h 9$ may be closely linked to the Est 9 locus. The location of $R p h 9$ in that region was confirmed by linkage with the dehydrin-9 (HVDHN9) microsatellite marker. HVDHN9 recently was mapped to chromosome $7(5 \mathrm{H})$ in the Harrington/TR306 population (22) and is positioned $\approx 12 \mathrm{cM}$ from RFLP marker CDO504 (M. Saghai Maroof, personal communication).

In a previous study, Rph12 was shown to be linked with the chromosome $7(5 \mathrm{H})$ morphological trait loci rawl and srh, with recombination values of $26.1 \pm 2 \%$ and $39.3 \pm 3 \%$, respectively (14). In this study, Rph12 was linked with the $v a$ locus at a distance of $22.6 \mathrm{cM}$. Loci $v a$ and rawl were positioned on the chromosome $7(5 \mathrm{H})$ map of morphological markers at a distance of 25.3 and $29.9 \mathrm{cM}$ from the srh locus, respectively (32). Recently, the morphological marker $v a$ was integrated into the molecular marker map of chromosome $7(5 \mathrm{H})$ in the Steptoe/Morex population (19). This marker showed linkage to $A B C 717$ in bulked segregant analysis. These data, together with those generated in the current study, place $v a$ in a region of chromosome $7(5 \mathrm{H})$ with a 33-cM gap with respect to mapped RFLP markers in the Steptoe/Morex population (17). Amplified fragment length polymorphisms (AFLPs) can generate more polymorphic markers than PCR or RFLP markers (26). However, in a recent study, AFLPs failed to generate additional markers in this gap in the Proctor/Nudinka barley population (2). $H V D H N 7$ and $H V D H N 9$ are two additional markers recently mapped to this chromosome $7(5 \mathrm{H})$ region (22); unfortunately, they were not polymorphic in the Triumph/I91-533-va population.

Although 14 leaf rust resistance genes have been identified in barley (13), only a few of them have been mapped to specific regions on the chromosomes. Rph4 from barley line Gold has been placed in the chromosome $5(1 \mathrm{H})$ linkage group, using the Reg1 $(\mathrm{Ml}-\mathrm{a})$ powdery mildew resistance gene as a genetic marker (23). Leaf rust resistance genes $R p h 10$ and $R p h 11$ from $H$. vulgare ssp. spontaneum were mapped to chromosomes $3(3 \mathrm{H})$ and $6(6 \mathrm{H})$, respectively, using their linkage with isozymes markers (8). Recently, Rph 2 was mapped to the centromeric region of chromosome $7(5 \mathrm{H})$, using molecular markers (3). The evidence reported here indicates Hor 2596 and Triumph carry a leaf rust resistance gene at the same locus on the long arm of chromosome $7(5 \mathrm{H})$ of barley. The locus designation of Rph12 was assigned to the gene in Triumph (14) before proper allelism tests were conducted. From a classical genetic point of view and considering the large number of $\mathrm{F}_{2}$ progeny evaluated in the allelism test, it appears that the gene in Triumph is indeed an allele at the Rph9 locus. Thus, the Rph12 designation should be changed to the allele designation of $R p h 9 . z$ according to the proposed nomenclature system of Frankowiak et al. (9) for leaf rust resistance genes in barley. The recommended allele designation for the Rph gene in Hor 2596 is Rph9.i.

Unlike the unimproved line Hor 2596, Trumpf and its export selection Triumph have been widely used in commercial barley production in several regions of the world. However, both of them have succumbed to damage by virulent pathotypes of $P$. hordei $(7,15)$. The resistance found in Triumph may be useful in North America, however, because pathotypes of $P$. hordei with virulence for Rph12 have not been detected (B. J. Steffenson and T. G. Fetch, unpublished data).

\section{ACKNOWLEDGMENTS}

This work was supported in part by the American Malting Barley Association and the North American Barley Genome Mapping Project. We thank S. Bennett for excellent technical assistance.

\section{LITERATURE CITED}

1. Becker, J., and Heun, M. 1995. Barley microsatellites: Allele variation and mapping. Plant Mol. Biol. 27:835-845.

2. Becker, J., Vos, P., Kuiper, M., Salamini, F. G., and Heun, M. 1995. Combined mapping of AFLP and RFLP markers in barley. Mol. Gen. Genet. 249:65-73.

3. Borovkova, I. G., Jin, Y., Steffenson, B. J., Kilian, A., Blake, T. K., and Kleinhofs, A. 1997. Identification and mapping of a leaf rust resistance gene in barley line Q21861. Genome 40:236-241.

4. Borovkova, I. G., Steffenson, B. J., Jin, Y., Rasmussen, J. B., Kilian, A., Kleinhofs, A., Rossnagel, B. G., and Kao, K. N. 1995. Identification of molecular markers linked to the stem rust resistance gene rpg4 in barley. Phytopathology 85:181-185.

5. Clifford, B. C. 1985. Barley leaf rust. Pages 173-205 in: The Cereal Rusts: Diseases, Distribution, Epidemiology, and Control. Vol. 2. A. P. Roelfs and W. R. Bushnell, eds. Academic Press, Orlando, FL.

6. Clifford, B. C., and Jones, E. R. L. 1982. Brown rust of barley. Pages 7071 in: The U.K. Cereal Pathogen Virulence Survey 1981 Annual Report. U.K. Cereal Pathogen Virulence Survey Committee, Cambridge.

7. Cotterill, P. J., Rees, R. G., and Vertigan, W. A. 1992. Detection of Puccinia hordei isolates virulent on the Pa9 and Triumph resistance genes in barley in Australia. Aust. Plant Pathol. 21:32-34.

8. Feuerstein, U., Brown, A. H. D., and Burdon, J. J. 1990. Linkage of rust resistance genes from wild barley (Hordeum spontaneum) with isozyme markers. Plant Breed. 104:318-324.

9. Frankowiak, J. D., Jin, Y., and Steffenson, B. J. 1997. Recommended allele symbols for leaf rust resistance genes in barley. Barley Genet. Newsl. 27:36-44.

10. Griffey, C. A., Das, M. K., Baldwin, R. E., and Waldenmayer, C. M. 1994. Yield loss in winter barley resulting from a new race of Puccinia hordei in North America. Plant Dis. 78:256-260.

11. Hvid, S., and Nielsen, G. 1977. Esterase isoenzyme variants in barley. Hereditas 87:155-162.

12. Islam, A. K. M. R. 1983. Ditelosomic additions of barley chromosomes to wheat. Pages 233-238 in: Proc. 6th. Int. Wheat Genet. Symp. S. Sakamoto, ed. Kyoto University Press, Kyoto, Japan.

13. Jin, Y., Cui, G. H., Steffenson, B. J., and Frankowiak, J. D. 1996. New leaf rust resistance genes in barley and their allelic and linkage relations with other Rph genes. Phytopathology 86:887-890.

14. Jin, Y., Statler, G. D., Frankowiak, J. D., and Steffenson, B. J. 1993. Link- 
age between leaf rust resistance genes and morphological markers in barley. Phytopathology 83:230-233.

15. Jones, E. R. L., and Clifford, B. C. 1984. Brown rust of barley. Pages 5-7 in: U.K. Cereal Pathogen Virulence Survey 1983 Annual Report. U.K. Cereal Pathogen Virulence Survey Committee, Cambridge.

16. Kleinhofs, A. 1996. NABGMP mapping update. Barley Genet. Newsl. 25:62-70.

17. Kleinhofs, A., Kilian, A., Saghai Maroof, M. A., Biyashev, R. H., Hayes, P., Chen, F. Q., Lapitan, N., Fenwick, A., Blake, T. K., Kanazin, V., Ananiev, E., Dahleen, L., Kudrna, D., Bollinger, J., Knapp, S. J., Liu, B., Sorrells, M., Heun, M., Frankowiak, J. D., Hoffman, D., Skadsen, R., and Steffenson, B. J. 1993. A molecular, isozyme and morphological map of the barley (Hordeum vulgare) genome. Theor. Appl. Genet. 86:705-712.

18. Kosambi, D. D. 1944. The estimation of map distances from recombination values. Ann. Eugen. 12:172-175.

19. Kudrna, D., Kleinhofs, A., Kilian, A., and Soule, J. 1996. Integrating visual markers with the Steptoe $\times$ Morex RFLP map. Page 343 in: Proc. 7th Int. Barley Genet. Symp. A. Slinkard, G. Scoles, and B. Rossnagel, eds. University Extension Press, Saskatoon, SK, Canada.

20. Lander, E. S., Green, P., Abrahamson, J., Barlow, A., Daly, M. J., Lincoln, S. E., and Newburg, L. 1987. MAPMAKER: An interactive computer package for constructing primary genetic linkage maps of experimental and natural populations. Genomics 1:174-181.

21. Levine, M. N., and Cherewick, W. J. 1952. Studies on dwarf leaf rust of barley. U.S. Dep. Agric. Tech. Bull. 1056.

22. Liu, Z.-W., Biyashev, R. M., and Saghai Maroof, M. A. 1996. Development of simple repeat DNA markers and their integration into a barley linkage map. Theor. Appl. Genet. 93:869-876.

23. McDaniel, M. E., and Hathcock, B. R. 1969. Linkage of Pa4 and Ml-a loci in barley. Crop Sci. 9:822.

24. Michelmore, R. W., Paran, I., and Kesseli, R. V. 1991. Identification of markers linked to disease-resistance genes by bulked segregant analysis: A rapid method to detect markers in specific genomic regions by using segregation populations. Proc. Natl. Acad. Sci. USA 88:9828-9832.
25. Roane, C. W., and Starling, T. M. 1967. Inheritance of reaction to Puccinia hordei in barley. II. Gene symbols for loci in differential populations. Phytopathology 57:66-68.

26. Russel, J. R., Fuller, J. D., Macaulay, M., Hatz, B. G., Jahoor, A., Powell, W., and Waugh, R. 1996. Direct comparisons of levels of genetic variation among barley accessions detected by RFLPs, AFLPs, SSRs and RAPDs. Pages 295-297 in: Proc. 7th Int. Barley Genet. Symp. A. Slinkard, G. Scoles, and B. Rossnagel, eds. University Extension Press, Saskatoon, SK, Canada.

27. Steffenson, B. J., Jin, Y., and Griffey, C. A. 1993. Pathotypes of Puccinia horde $i$ with virulence for the barley leaf rust resistance gene $R p h 7$ in the United States. Plant Dis. 77:867-869.

28. Steffenson, B. J., Jin, Y., Rossnagel, B. G., Rasmussen, J. B., and Kao, K. 1995. Genetics of multiple disease resistance in a doubled haploid population of barley. Plant Breed. 114:50-54.

29. Tan, B. H. 1977. A new gene for resistance to Puccinia hordei in certain Ethiopian barleys. Cereal Rusts Bull. 5:39-43.

30. Tragoonrung, S., Kanazin, V., Hayes, P. M., and Blake, T. K. 1992. Sequence-tagged-site-facilitated PCR for barley genome mapping. Theor. Appl. Genet. 84:1002-1008.

31. Udeogalanya, A. C. C., and Clifford, B. C. 1978. Genetical, physiological and pathological relationships of resistance to Puccinia hordei and Puccinia striiformis in Hordeum vulgare. Trans. Br. Mycol. Soc. 71: 279-287.

32. von Wettstein-Knowles, P. 1994. Cloned and mapped genes: Current status. Pages 73-98 in: Barley: Genetics, Biochemistry, Molecular Biology and Biotechnology. P. R. Shewry, ed. CAB International, Wallingford, England, U.K.

33. Walther, U. 1987. Inheritance of resistance to Puccinia hordei Otth in the spring barley variety Trumpf. Cereal Rusts \& Powdery Mildews Bull. 15: 106-107.

34. Yu, Y. G., Saghai Maroof, M. A., Buss, G. R., Maughan, P. J., and Tolin, S. A. 1994. RFLP and microsatellite mapping of a gene for soybean mosaic virus resistance. Phytopathology 84:60-64. 